\title{
THE STUDY METAL BINDING PROTEIN DOMINANT TYPES OF PLANTS AND MICROORGANISMS IN AGROBIOCENOSIS OF THE VOLGOGRAD REGION ${ }^{1}$
}

\author{
Valeriy V. Novochadov \\ Volgograd State University, Volgograd, Russian Federation \\ Elena A. Ivantsova \\ Volgograd State University, Volgograd, Russian Federation \\ Pavel A. Krylov \\ Volgograd State University, Volgograd, Russian Federation \\ Nikolay V. Onistratenko \\ Volgograd State University, Volgograd, Russian Federation \\ Anna V. Kholodenko \\ Volgograd State University, Volgograd, Russian Federation
}

\begin{abstract}
The use of modern bioinformatic approaches for the solution of environmentally oriented tasks provides new data that can be used for spot control anthropogenic ecosystems and ecosystem rebuilding of their violation obtained from adverse factors of natural and antropogenical genesis. This work aims at demonstrating and identifying metal binding proteins in dominant species of plants and microorganisms of agrocenosis that allows you to create an information database for accumulating and processing information about the regularities of the functioning of agro-ecosystem in arid conditions, leading to the growth of economic efficiency of the farming system and increase the success of environmental management.

The main purpose of the work was to study the presence of metal binding proteins included in the proteome, the dominant species of plants and microorganisms from three typical agrocenoses of the Volgograd region. Metal binding proteins were distributed not only in their functional features, participation in photosynthesis, salt resistance, but also in the degree of their dependence on specific metals: manganese, zinc and copper. The results of the proteinaceous analysis of metal binding proteins in plants and microorganisms showed that the main dominant species annotated a small amount of proteins, the most prominent representative is barley ordinary it described 246 metal-dependent proteins of which 115 annotated, in other plants the number of proteins is much lower, or not studied at all proteome. The soil microbiota of the considered agrocenosis is also characterized by a sufficiently large number of metal-dependent proteins, 4874 for representatives of the Genus Actinomyces and 5727 for Bacillus subtilis, of which about $45-50 \%$ are annotated. According to the results, the concentration of metals in the soil of agrocenosis, namely in the arid zone, has a very strong impact on the livelihoods of crops and microorganisms in the soil.

The use of the obtained results can be used as a basis for the implementation of targeted high-precision management of biocenoses in order to improve the sustainability of natural communities and the economic efficiency of agrocenoses.
\end{abstract}

Key words: agrocenoses, proteome, metal binding proteins, agricultural nature management, management of ecological communities, database.

Citation. Novochadov V.V., Ivantsova E.A., Krylov P.A., Onistratenko N.V., Kholodenko A.V. The Study Metal Binding Protein Dominant Types of Plants and Microorganisms in Agrobiocenosis of the Volgograd Region. Vestnik Volgogradskogo gosudarstvennogo universiteta. Seriya 3, Ekonomika. Ekologiya [Science Journal of Volgograd State University. Global Economic System], 2018, vol. 20, no. 4, pp. 173-182. (in Russian). DOI: https:// doi.org/10.15688/jvolsu3.2018.4.16 


\title{
ИССЛЕДОВАНИЕ МЕТАЛЛЗАВИСИМЫХ БЕЛКОВ ДОМИНИРУЮЩИХ ВИДОВ РАСТЕНИЙ И МИКРООРГАНИЗМОВ В АРИДНЫХ АГРОБИОЦЕНОЗАХ ВОЛГОГРАДСКОЙ ОБЛАСТИ ${ }^{1}$
}

\author{
Валерий Валерьевич Новочадов \\ Волгоградский государственный университет, г. Волгоград, Российская Федерация \\ Елена Анатольевна Иванцова \\ Волгоградский государственный университет, г. Волгоград, Российская Федерация \\ Павел Андреевич Крылов \\ Волгоградский государственный университет, г. Волгоград, Российская Федерация \\ Николай Владимирович Онистратенко \\ Волгоградский государственный университет, г. Волгоград, Российская Федерация
}

Анна Викторовна Холоденко

Волгоградский государственный университет, г. Волгоград, Российская Федерация

Аннотация. Использование современных биоинформационных подходов для решения эколого-ориентированных задач обеспечивает получение новых данных, которые можно использовать для импактного управления агроценозами и экосистемами, восстанавливая их нарушения, обусловленные действием неблагоприятных факторов естественной и антропогенной среды. Данная работа направлена на выявление и определение металлзависимых белков в доминирующих видах растений и микроорганизмов в зерновом агроценозе, что позволяет создать информационную базу для накопления и обработки сведений о закономерностях функционирования сельскохозяйственных систем в аридных условиях, что будет способствовать повышению эффективности природопользования.

Основной целью работы являлось изучение наличия металлзависимых белков, входящих в протеом доминирующих видов растений и микроорганизмов типичных агроценозов Волгоградской области. Металлзависимые белки распределялись не только по их функциональным особенностям, участию в фотосинтезе и солеустойчивости, но и по степени их зависимости от конкретных металлов - марганца, цинка и меди. Результаты протеомного анализа металлзависимых белков у растений и микроорганизмов свидетельствуют о незначительном количестве белков у основных доминирующих видов. Наибольшим количеством металлзависимых белков отличается Hordeum vulgare L. (ячмень обыкновенный) как основа агроценоза, для которого описано 246 белков, в том числе 115 аннотированных. У сопутствующих ценозообразователю сорных растений количество белков значительно ниже либо протеом не изучался. Для почвенной микробиоты рассмотренного агроценоза также характерно достаточно большое количество металлзависимых белков: 4874 - для представителей Рода Actinomyces и 5727 - для Bacillus subtilis, из которых примерно 45-50 \% аннотированы. Полученные результаты свидетельствуют, что концентрация металлов в почве агроценоза является значимым фактором воздействия на жизнедеятельность сельскохозяйственных культур и микроорганизмов в почве.

Полученные результаты можно использовать как основу для осуществления адресного высокоточного управления биоценозами с целью повышения устойчивости природных сообществ и экономической эффективности агроценозов.

Ключевые слова: агроценозы, протеом, металлзависимые белки, сельскохозяйственное природопользование, управление агроценозами, база данных.

Цитирование. Новочадов В. В., Иванцова Е. А., Крылов П. А., Онистратенко Н. В., Холоденко А. В. Исследование металлзависимых белков доминирующих видов растений и микроорганизмов в аридных агробиоценозах Волгоградской области // Вестник Волгоградского государственного университета. Серия 3, Экономика. Экология. - 2018. - Т. 20, № 4. - C. 173-182. - DOI: https://doi.org/10.15688/jvolsu3.2018.4.16 
Введение. В настоящее время наиболее актуальным подходом в развитии АПК является экологический системный подход к управлению агроценозами $[1 ; 2 ; 3]$. Модификация такого подхода возможна с использованием биотехнологических решений, в частности, управление путем внедрения в агроценоз новых элементов - биотических (бактерии и грибы) или же абиотических (химические вещества) $[4 ; 6 ; 8 ; 12 ; 14 ; 15 ; 17]$. Зависимость динамики вещества и энергии в агробиоценозах от влияния почвенно-климатических условий рассмотрена в ряде достаточно обширных исследований $[3 ; 10 ; 13]$.

Особое место в динамике агробиоценозов занимают взаимодействия с прилегающими природно-антропогенными системами, которые при активном воздействии на искусственные биоценозы приобретают характер интрузий с плотным переходом или частичной заменой территории искусственного биоценоза $[9 ; 14]$. Для участков техногенных вторжений в агроценозы оптимально точечное управление $[4 ; 6 ; 16]$, что приводит к негативным изменениям агроценоза и снижению эффективности его использования для решения экономических задач в целом, а также на территории Волгоградской области. Агроценозы этой территории характеризуются комплексом стрессовых факторов, оказывающих значительное влияние на перестройку метаболизма растений и микроорганизмов, обитающих на этих территориях $[3 ; 5 ; 10 ; 11]$. Все это подтверждает необходимость изучения молекулярного уровня организации агроценоза. Изучение металлзависимых белков, входящих в протеом сельскохозяйственных растений и микроорганизмов в почве, позволит выявить белки, участвующие в регулировании метаболизма. Полученные данные можно будет использовать для высокоточного управления за счет модуляции метаболизма как растений, так и микроорганизмов в агробиоценозе [7].

Цель работы - поиск и изучение металлзависимых белков доминирующих видов растений и представителей почвенной микробиоты агроценозов Волгоградской области.

Материалы и методы. Для изучения протеома и металлзависимых белков были отобраны доминирующие виды растений в трех агроценозах, территориально локализованных:
Городищенский (аллея Ракутина) и Светлоярский (агрохозяйственая зона) муниципальные районы Волгоградской области и Советский район г. Волгограда (Горная поляна). Следующим этапом стало проведение биоинформационного анализа с использованием виртуального скрининга базы UniProt (www.uniprot. org) и GeneOntology (http://geneontology.org). Предварительно были выбраны металлы: марганец, никель, кобальт, медь и цинк. Скрининг осуществлялся по следующим критериям: наличие в составе белка искомых металлов и возникновение взаимодействия с металлом. Для поиска использовались синонимические конструкты следующего типа zincANDorganism: "Artemisiaabsinthium (Absinthwormwood) [72332]”. Производился поиск по металлам, входящим в кофактор, а также по атомам - в металлсвязывающих сайтах. Таким образом проводился отбор всех металлзависимых белков, которые содержат металл в своей структуре либо связываются с металлом для проявления своей активности. Структура базы знаний о металлзависимых белках строилась с помощью MicrosoftExel (США) и включала в себя следующие строки: по горизонтали название вида, названия металлов, по вертикали функции белков в организме, названия белков, id белков в UniProt. Также по вертикали включены данные из GeneOntology, которые позволяют более подробно отразить функционирование белка, эти сведения были найдены и для белков, у которых не аннотировано функций в UniProt. У металлзависимых белков были выбраны основные функции: фотосинтез (Фотосистема II), солеустойчивость, дыхательная цепь. У микроорганизмов: фотосинтез, дыхательная цепь, транспорт и метаболизм. Окончательная структура базы знаний о металлзависимых белках может быть расширена за счет включения новых параметров, таких как состав кофактора или металлсвязывающего сайта, ссылки на публикации в PubMed.

Результаты и их обсуждение. Произведен поиск металлазвисимых белков представителей доминирующих видов растений и микроорганизмов агробиоценозов Волгоградской области в UniProt. Поиск проводился по названиям организмов, металлы регистрировались в графах по Functions / Cofactors и Function / Sites / Metalbinding. Все белки, содержащие и связывающие металлы, были разделены по входящим 
в них металлам и выполняемым функциям. В процессе изучения протеома растений было выяснено, что среди всех представителей агробиоценоза металлзависимые белки аннотированы у 6 видов: Amaranthus retroflexus L., Medicago sativa L., Melilotus officinalis L. Pall., Polygonum aviculare L., Convolvulus arvensis L., Hordeum vulgare L. (табл. 1).

Не аннотированы металлзависимые белки по следующим представителям агробиоценоза: Atriplex tatarica L., Lactuca tatarica L., Xanthium albinum (Widd.) H. Scholz \& Sukopp, Vincetoxicum scandens (Kusn.) Litv., Descurainia sophia L., Lycopsis arvensis L., Tripleurospermum inodorum Sch. Bip., Rumex confertus W., Crepis tectorum L., Artemisia absinthium L., Cichorium intybus L., Delphrnium dictyocarpum DC, Euphorbia seguieriana Neck., Lepidium perfoliatum L., Convolvulus arvensis L., Elytrigia repens (L.) Nevski, Euphorbia helioscopia L., Consolida regalis L., Artemisia austriaca Jacq., Artemisia lercheana Web. ex Stechm., Tragopogon dubius Scop., Delphinium consolida L., Achillea micrantha Willd., Stipa capillata L., Silene wolgensis Willd., Bromopsis inermis Holub., Bryum argenteum Hedw., Bromus inermis Leyss. , Filago arvensis L., Achillea millefolium L., Salvia aethiopis L., Centaurea ruthenica Lam., Poa pratensis L., Euphorbia seguieriana Neck, Scorzonera mollis M. Bieb., Lolium perenne L., Centaurea diffusa Lam, Onobrychis arenaria Kit., Medicago falcate L., Thlaspi arvense L., Turgenia latifolia L., Raphanus raphanistrum $L$.
Металлзависимые белки аннотированных в UniProt представителей агробиоценоза отвечают за выполнение функций, таких как фотосинтез (фотосистема II), регуляция клеточного цикла и метаболизма, биосинтез пигментов, участие в дыхательной цепи. Среди растений найдены такие металлзависимые белки, как марганец, медь и цинк.

У Amaranthus retroflexus L. как и Convolvulus arvensis L. по марганцу аннотированы 2 белка, отвечающие за фотосинтез, для Amaranthus retroflexus L. также выделены 2 белка по цинку с неизвестной функцией. У Medicago sativa L. аннотировано наибольшее количество металлзависимых белков 27, 6 из которых связаны с марганцем и ответственны за функцию фотосинтеза, и 1 белок, содержащий медь, участвующий в дыхательной цепи. Остальные 10 белков, связанных с цинком, отвечают за уничтожение радикалов в клетках, солеустойчивость, протеолитическую активность, лигнификацию, регуляцию метаболизма и участие в обратимой гидратации углекислого газа.

У Melilotus officinalis L. Pall. найдены 6 белков, содержащих медь и марганец, отвечающих за фотосинтез и клеточное дыхание. У Polygonum aviculare L. найдены 2 белка, включающие медь и участвующие в дыхательной функции. В вегетативных органах Artemisia absinthium L. металлзависимых белков обнаружено не было. Hordeum vulgare L. имеет 246 металлзависимых белка, из которых 115 аннотированы по марганцу (22), меди (3) и цинку (90). Белки, содержащие цинк, выполняют метабо-

Металлзависимые белки, входящие в протеом доминирующих видов растений и почвенной микробиоты в агроценозах Волгоградской области (по данным UniProt)

\begin{tabular}{|c|c|c|c|c|c|c|c|}
\hline \multirow[t]{2}{*}{$\begin{array}{c}\text { Вид растения, } \\
\text { произрастающего } \\
\text { в агроценозе }\end{array}$} & \multirow{2}{*}{$\begin{array}{c}\text { Общее коли- } \\
\text { чество ме- } \\
\text { таллзависи- } \\
\text { мых белков } \\
\end{array}$} & \multicolumn{3}{|c|}{$\begin{array}{c}\text { Металлзависимые } \\
\text { белки с аннотирован- } \\
\text { ными функциями }\end{array}$} & \multicolumn{3}{|c|}{$\begin{array}{c}\text { Металлзависимые } \\
\text { белки без аннотиро- } \\
\text { ванных функций }\end{array}$} \\
\hline & & $\mathrm{Mn}$ & $\mathrm{Cu}$ & $\mathrm{Zn}$ & $\mathrm{Mn}$ & $\mathrm{Cu}$ & $\mathrm{Zn}$ \\
\hline \multicolumn{8}{|c|}{ Растения } \\
\hline Amaranthus retroflexus $L$. & 4 & 2 & - & - & - & - & 2 \\
\hline Medicago sativa $L$ & 27 & 9 & 4 & 10 & 2 & - & 2 \\
\hline Melilotus officinalis L. Pall. & 6 & 4 & 2 & - & - & - & - \\
\hline Polygonum aviculare L. & 2 & - & 2 & - & - & - & - \\
\hline Convolvulus arvensis $L$. & 2 & 2 & - & - & - & - & - \\
\hline Hordeum vulgare L. & 246 & 22 & 3 & 90 & 11 & 13 & 107 \\
\hline \multicolumn{8}{|c|}{ Почвенная микробиота } \\
\hline Bacillus subtilis & 5727 & 659 & 175 & 2045 & 574 & 301 & 1973 \\
\hline Pod Actinomyces & 4874 & 404 & 30 & 1906 & 545 & 246 & 1743 \\
\hline
\end{tabular}


Исследование металлзависимых белков доминирующих видов растений и микроорганизмов

лические функции, а также участвуют в убиквитинировании и последующей протеасомальной деградации целевых белков. Белки, связан- ные с марганцем, ответственны за образование $\mathrm{S}$-аденозилметионина из метионина и АТФ, участвуют в защитных механизмах (табл. 2).

Таблица 2

Описание металлзависимых белков, входящих в протеом доминирующих видов растений в агроценозах Волгоградской области

\begin{tabular}{|c|c|}
\hline \multicolumn{2}{|r|}{ Amaranthus retroflexus $L$. } \\
\hline \multirow{2}{*}{ Металлы } & Функции \\
\hline & Фотосинтез (Фотосистема II) \\
\hline $\mathrm{Mn}$ & Q09JC5 / Photosystem II protein D1, Q09JC4 / Photosystem II protein D1 \\
\hline $\mathrm{Cu}$ & - \\
\hline $\mathrm{Zn}$ & E3VW74 / Pollen allergen MetE, A0A0G2UR02 / 4,5-dioxygenase-like protein \\
\hline \multicolumn{2}{|r|}{ Medicago sativa $L}$. \\
\hline \multicolumn{2}{|r|}{ Фотосинтез (Фотосистема II) } \\
\hline $\mathrm{Mn}$ & $\begin{array}{l}\text { A0A1B3T069 / Photosystem II CP43 reaction center protein, A0A109RT53 / Photosystem II CP43 reaction } \\
\text { center protein, A0A109RSW1 / Photosystem II protein D1, A0A1J0I0J9 / Photosystem II protein D1, } \\
\text { A0A1J0I0H6 / Photosystem II CP43 reaction center protein, P04998 / Photosystem II protein D1 }\end{array}$ \\
\hline $\mathrm{Cu}$ & (2) \\
\hline \multirow[t]{2}{*}{$\mathrm{Zn}$} & - \\
\hline & Дыхательная цепь \\
\hline $\mathrm{Mn}$ & - \\
\hline $\mathrm{Cu}$ & A0A110BEA8 / Cytochrome c oxidase subunit 1 \\
\hline \multirow[t]{2}{*}{$\mathrm{Zn}$} & e \\
\hline & Солеустойчивость \\
\hline $\mathrm{Mn}$ & - \\
\hline $\mathrm{Cu}$ & - \\
\hline $\mathrm{Zn}$ & O82515 / Probable mannitol dehydrogenase \\
\hline \multicolumn{2}{|r|}{ Polygonum aviculare L. } \\
\hline & Дыхательная цепь \\
\hline $\mathrm{Mn}$ & - \\
\hline $\mathrm{Cu}$ & B5LE17 / Cytochrome c oxidase subunit 1, B5LE18 / Cytochrome c oxidase subunit 1 \\
\hline $\mathrm{Zn}$ & 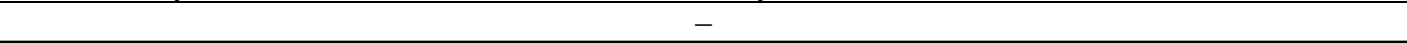 \\
\hline \multicolumn{2}{|r|}{ Melilotus officinalis L. } \\
\hline \multicolumn{2}{|r|}{ Фотосинтез (Фотосистема II) } \\
\hline $\mathrm{Mn}$ & $\begin{array}{l}\text { A0A0K0LTI4 / Photosystem II CP43 reaction center protein, A0A0K0LTP9 / Photosystem II protein D1, } \\
\text { A0A0K0LU62 / Photosystem II protein D1, A0A0K0LTJ5 / Photosystem II CP43 reaction center protein }\end{array}$ \\
\hline $\mathrm{Cu}$ & 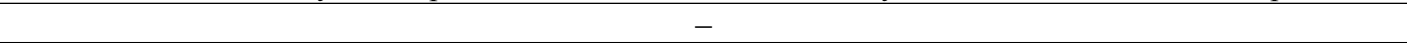 \\
\hline \multirow[t]{2}{*}{$\mathrm{Zn}$} & - \\
\hline & Дыхательная цепь \\
\hline $\mathrm{Mn}$ & 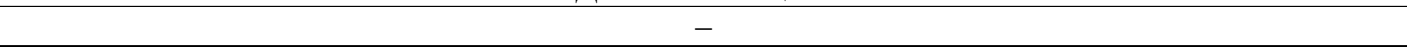 \\
\hline $\mathrm{Cu}$ & A0A110BC78 / Cytochrome c oxidase subunit 1, A0A109RU10 / Cytochrome c oxidase subunit 1 \\
\hline $\mathrm{Zn}$ & - \\
\hline \multicolumn{2}{|r|}{ Convolvulus arvensis L. } \\
\hline \multicolumn{2}{|r|}{ Фотосинтез (Фотосистема II) } \\
\hline \multicolumn{2}{|r|}{ Amaranthus retroflexus $L}$. \\
\hline $\mathrm{Mn}$ & Photosystem II CP43 reaction center protein, Photosystem II protein D1 \\
\hline $\mathrm{Cu}$ & -2 \\
\hline $\mathrm{Zn}$ & - \\
\hline \multicolumn{2}{|r|}{ Hordeum vulgare L. } \\
\hline \multicolumn{2}{|r|}{ Фотосинтез (Фотосистема II) } \\
\hline $\mathrm{Mn}$ & Photosystem II CP43 reaction center protein, Photosystem II protein D1 \\
\hline $\mathrm{Cu}$ & -1 \\
\hline \multirow[t]{2}{*}{$\mathrm{Zn}$} & - \\
\hline & Дыхательная цепь \\
\hline $\mathrm{Mn}$ & S-adenosylmethionine synthase, S-adenosylmethionine synthase 2, S-adenosylmethionine synthase 3 \\
\hline $\mathrm{Cu}$ & Cytochrome c oxidase subunit 1 , Cytochrome $\mathrm{c}$ oxidase subunit 2 \\
\hline $\mathrm{Zn}$ & - \\
\hline
\end{tabular}


Установлено, что мелаллсодержащие белки отвечают за различные функции, такие как участие в фотосинтезе (преимущественно белки, содержащие марганец), в дыхании (медьсодержащие белки). Белки, содержащие цинк, участвуют в выполнении таких специфических функций, как лигнификация, синтез душистых веществ растения, а также поддержание солеустойчивости, регуляция синтеза жирных кислот.

В базе UniProt по Actinomyces weissii как основному представителю рода Actinomyces найдены 2 белка - шаперонины, которые не включают в себя металлы. В целом для рода Actinomyces, обнаружены 1906 цинкзависимых белков с аннотированными функциями и еще 1743 белков, связанных с цинком, без аннотированных функций. Большая часть белков, включающих цинк, выполняет функцию регуляции экспрессии генов. Среди белков, связывающих медь, найдены 30 с аннотирован- ными функциями и 246 без аннотированных функций. Основная часть белков, включающих в состав медь, участвует в дыхательной цепи и связывании меди.

У представителей почвенной микробиоты аннотированные металлзависимые белки обнаружены у Bacillus subtilis, для которого они участвуют в регулировании ряда функций: участие в метаболизме, регуляция транспорта, фотосинтез (табл. 3). У представителей Bacillus subtilis функции в большинстве случаев связаны с белками, содержащими металлы. За функцию метаболизма ответственно большинство белков, связанных со всеми тремя металлами, среди которых цинк является наиболее значимым. Марганец в большей степени вовлечен в процессы гидролиза и разрушения биологических молекул, медь в основном участвует в дыхании, как и у растений, а цинк в большей степени - в превращении веществ, синтезе. В протеолитической ак-

Таблица 3

\section{Описание металлзависимых белков, входящих в протеом доминирующих представителей почвенной микробиоты агроценозов Волгоградской области}

\begin{tabular}{|c|c|}
\hline \multicolumn{2}{|r|}{ Род Actinomyces } \\
\hline \multirow[t]{2}{*}{ Металлы } & Функции \\
\hline & Дыхательная цепь \\
\hline $\mathrm{Mn}$ & - \\
\hline $\mathrm{Cu}$ & Cytochrome c oxidase subunit 1 \\
\hline \multirow[t]{2}{*}{$\mathrm{Zn}$} & J tor \\
\hline & Метаболизм \\
\hline $\mathrm{Mn}$ & $\begin{array}{l}\text { 2-succinyl-5-enolpyruvyl-6-hydroxy-3-cyclohexene-1-carboxylate } \\
\text { aminopeptidase, D-alanine--D-alanineligasa }\end{array}$ \\
\hline $\mathrm{Cu}$ & 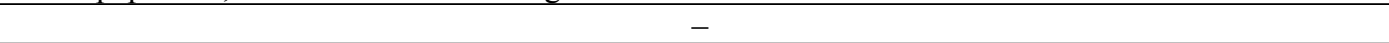 \\
\hline $\mathrm{Zn}$ & 3-isopropylmalate dehydrogenase, ATP-dependent zinc metalloprotease FtsH, Ribonuclease J. \\
\hline \multicolumn{2}{|r|}{ Bacillus subtilis } \\
\hline \multicolumn{2}{|r|}{ Метаболизм } \\
\hline $\mathrm{Mn}$ & $\begin{array}{l}\text { Riboflavin biosynthesis protein RibBA, GTPcyclohydrolase-2, 2,3-bisphosphoglycerate-independent } \\
\text { phosphoglycerate mutase, Putative ADP-ribose pyrophosphatase YjhB, Alpha-galacturonidase, } \\
\text { Inososedehydratase, 4-hydroxy-2-oxovalerate aldolase, 2-succinyl-5-enolpyruvyl-6-hydroxy-3-cyclohexene- } \\
\text { 1-carboxylate synthase, Tyrosine-protein phosphatase YwqE, Arginase, 1-deoxy-D-xylulose 5-phosphate } \\
\text { reductoisomerase, 3-isopropylmalate dehydrogenase, Phosphopentomutase, Oxalate decarboxylase OxdC, } \\
\text { Probable cytosol aminopeptidase, L-arginine-specific L-amino acid ligase, Methionine aminopeptidase 2, } \\
\text { Ribonuclease HII, Putative peptide zinc metalloprotease protein YydH, Isoleucine-tRNA ligase, UvrABC } \\
\text { system protein }\end{array}$ \\
\hline $\mathrm{Cu}$ & 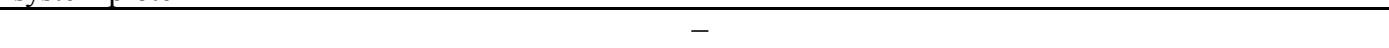 \\
\hline $\mathrm{Zn}$ & $\begin{array}{l}\text { HTH-type transcriptional repressor CzrA, 50S ribosomal protein L31 type B, Zinc-specific metallo- } \\
\text { regulatory protein, Queuine tRNA-ribosyltransferase, Endoribonuclease YbeY, Primosomal protein N', } \\
\text { Transcriptional repressor NrdR, Alanine--tRNA ligase, Threonine--tRNA ligase, Glutamate--tRNA ligase, } \\
\text { DNA primase, Small ribosomal subunit biogenesis GTPase RsgA, 30S ribosomal protein S14 type Z, ComE } \\
\text { operon protein 2, Ribonuclease Z, Phosphomethylpyrimidine synthase, Formamidopyrimidine-DNA } \\
\text { glycosylase, Methionine-tRNA ligase, Cytidine deaminase, Ribonuclease J2, Ribonuclease J }\end{array}$ \\
\hline
\end{tabular}


Исследование металлзависимых белков доминирующих видов растений и микроорганизмов

Окончание таблицы 3

\begin{tabular}{|c|c|}
\hline & Дыхательная цепь \\
\hline $\mathrm{Mn}$ & Formimidoylglutamase, Putative 8-oxo-dGTPdiphosphatase \\
\hline $\mathrm{Cu}$ & $\begin{array}{l}\text { Cytochrome c oxidase subunit 1, Quinol oxidase subunit 1, Copper-sensing transcriptional repressor } \\
\text { CsoR, Cytochrome c oxidase subunit } 2 \text {, Copper homeostasis protein CutC, Copper transport protein } \\
\text { YcnJ, Polyphenol oxidase, Multidrug efflux protein } \mathrm{YfmO}\end{array}$ \\
\hline \multirow[t]{2}{*}{$\mathrm{Zn}$} & $\begin{array}{l}\text { Molybdopterin-synthase adenylyltransferase, Allantoate amidohydrolase, 7-cyano-7-deazaguanine } \\
\text { synthase, Phosphoribosyl-AMP cyclohydrolase, Protein translocase subunit SecA, Probable fructose- } \\
\text { bisphosphate aldolase, Adenylate kinase, 5-methylthioadenosine/S-adenosyl homocysteine deaminase, } \\
\text { tRNA-specific adenosine deaminase, Methylthioribulose-1-phosphate dehydratase, 4-deoxy-L-threo-5- } \\
\text { hexosulose-uronate ketol-isomerase, Phosphoheptose isomerase, Acetyl-coenzyme A carboxylase } \\
\text { carboxyl transferase subunit beta, Metal-dependent carboxypeptidase, N-formyl-4-amino-5- } \\
\text { aminomethyl-2-methylpyrimidine deformylase, Guanine deaminase, L-threonine 3-dehydrogenase }\end{array}$ \\
\hline & Транспорт \\
\hline $\mathrm{Mn}$ & $\begin{array}{l}\text { Sporulation protein, Manganese efflux pump MntP, Membrane protein, Putative membrane protein, } \\
\text { Integral inner membrane protein, Divalent metal cation transporter MntH, Manganese transport } \\
\text { system ATP-binding protein MntB, }\end{array}$ \\
\hline \multicolumn{2}{|r|}{ Род Actinomyces } \\
\hline $\mathrm{Cu}$ & $\begin{array}{l}\text { Copper-exporting P-type ATPase, SCO1 protein homolog, HTH-type transcriptional repressor YcnK, } \\
\text { Copper chaperone CopZ, HTH-type transcriptional regulator YfmP, }\end{array}$ \\
\hline $\mathrm{Zn}$ & High-affinity zinc uptake system binding-protein ZnuA, Zinc-transporting ATPase \\
\hline & Фотосинтез \\
\hline $\mathrm{Mn}$ & - \\
\hline $\mathrm{Cu}$ & Plastocyanin \\
\hline $\mathrm{Zn}$ & - \\
\hline
\end{tabular}

тивности не участвуют белки, связанные с марганцем и медью. Белки, содержащие цинк, участвуют в транспортной системе Bacillus subtilis в качестве распределителей энергии АТФ. В транспорте веществ также участвуют белки, содержащие марганец и медь. Белки, содержащие цинк, участвуют также в защитных механизмах, в отличие от остальных металлзависимых белков. В обеспечении фотосинтеза участвует только один аннотированный медьсодержащий белок - пластоцианин.

Сравнивая металлзависимые белки доминирующих видов растений и представителей почвенной микробиоты, можно отметить, что металлсодержащие белки отвечают за формирование защитных механизмов (солеустойчивость и лигнификация клеток) относительно внешних стрессовых факторов, характерных для аридной зоны.

В фотосинтезе и энергетических обменах у растений, как и у представителей Bacillus subtilis, преобладают содержащие марганец и медь белки, что связано с производством АТФ и его использованием. Это может быть связано как с адаптацией к условиям окружающей среды на энергетическом уровне, так и с транспортом веществ через мембрану. Ocновными адаптационными функциями, исходя из аннотирования металлзависимых белков, являются транспортная и метаболическая.

Заключение. Поиск и анализ металлзависимых белков, входящих в протеом доминирующих растений и почвенной микробиоты, показали, что на сегодняшний момент белковый состав не изучен у большинства произрастающих растений, входящих в состав типичных агроценозов аридной зоны на территории Волгоградской области. Данные, полученные в ходе исследования, могут быть использованы для высокоточного управления развитием агроценозов путем воздействия на металлзависимые механизмы растений и представителей почвенной микробиоты для обеспечения необходимого уровня эффективного природопользования и достижения оптимального экономического эффекта.

\section{ПРИМЕЧАНИЕ}

${ }^{1}$ Публикация подготовлена при финансовой поддержке Государственного задания Минобрнауки РФ по теме «Разработка экологоориентированных биотехнологий оптимизации аридных агробиоценозов Юга России на основе достижений физико-химической биологии и биоинформатики» (проект № 40.7534.2017/8.9). 


\section{СПИСОК ЛИТЕРАТУРЫ}

1. Дудченко, Л. В. Эффективный биологический способ подавления сорных растений в полезащитных лесных насаждениях / Л. В. Дудченко // Достижения науки и техники АПК. - 2012. - № 7. C. 37-38.

2. Зубков, А. Ф. Агробиоценологическая модернизация защиты растений / А. Ф. Зубков. - СПб. : ВИЗР, 2014. - 116 с. - (Приложение к журналу «Вестник защиты растений», № 12).

3. Мушаева, К. Б. Оценка современного состояния агропастбищных ландшафтов полупустынной зоны республики Калмыкия с применением ГИС-технологий / К. Б. Мушаева // Вестник Волгоградского государственного университета. Серия 11, Естественные науки. - 2015. - № 1. - С. 103-110.

4. Снижение негативного воздействия на агроценозы путем управления примыкающими природно-антропогенными системами / Е. А. Иванцова [и др.] // Вестник Волгоградского государственного университета. Серия 3: Экономика. Экология. 2017. - T. 19, № 4 (41). - C. 138-146. -DOI: 10.15688/ jvolsu3.2017.4.15.

5. Трифонова, Т. А. Моделирование стационарных состояний системы фитоценоз-почва (на примере бассейна р. Клязьма) / Т. А. Трифонова, Л. А. Ширкин, Н. В. Мищенко // Почвоведение. 2012. - № 8. - C. 889 .

6. A functional trait perspective on plant invasion / R. E. Drenovsky [et al.] // Ann. Bot. - 2012. - Vol. 110, № 1. - P. 141-153. - DOI: 10.1093/aob/mcs100.

7. Biochemical and molecular mechanisms of plant-microbe-metal interactions: relevance for phytoremediation / Y. Ma [et al.] // Front Plant Sci. 2016. - Vol. 7. - DOI: 10.3389/fpls.2016.00918

8. Biotic and abiotic drivers of intraspecific trait variation within plant populations of three herbaceous plant species along a latitudinal gradient / K. Helsen, [et al.] // BMC Ecol. -2017. - № 17. - P. 38.

9. Ecological aspects of phytosanitary optimization of arid agrobiocenoses of the south of Russia / E. A. Ivantsova [et al.] // Bulgarian J. Agric. Sci. - 2017. - Vol. 23, № 5. - P. 834-842.

10. In vitro antagonistic activity, plant growth promoting traits and phylogenetic affiliation of rhizobacteria associated with wild plants grown in arid soil /W. S. El-Sayed [et al.] // Front. Microbiol.-2014. - Vol. 5.

11. Influence of life form, taxonomy, climate, and soil properties on shoot and root concentrations of 11 elements in herbaceous plants in a temperate desert / M. He [et al.] // Plant and Soil. - 2016. - Vol. 398, № 102.P. 339-350.

12. Invasive plants rapidly reshape soil properties in a grassland ecosystem / S. M. Gibbons [et al.] // mSystems. - 2017. - Vol. 2, № 2.
13. Leaf nitrogen and phosphorus of temperate desert plants in response to climate and soil nutrient availability / M. He [et al.] // Scientific Reports. - 2014.№ 4. -P. 6932. -DOI: https://doi.org/10.1038/srep06932.

14. Phylogenetic plant community structure along elevation is lineage specific / C. Ndiribe [et al.] // Ecology and Evolution. - 2013. - Vol. 3, № 15. P. 4925-4939.

15. Plant communities in harsh sites are less invaded: a summary of observations and proposed explanations / E. Zefferman [et al.] // AoBPlants. - 2015. - № 7 .

16. Synergistic effects of the components of global change: Increased vegetation dynamics in open, forest-steppe grasslands driven by wildfires an d yearto-year precipitation differences / M. Kertész, R. Aszalós, A. Lengyel, G. Ónodi // PLoS One. - 2017. Vol. 12, № 11 .

17. The database of the PREDICTS (Projecting Responses of Ecological Diversity In Changing Terrestrial Systems) project / L. N. Hudson [et al.] // Ecol. Evol.-2017. - Vol. 7, № 1.-P. 145-188.

\section{REFERENCES}

1. Dudchenko L.V. Effectivniy biologicheskiy sposob podavleniya sornykh rasteniy $\mathrm{V}$ polezashchitnykh lesnyh nasazhdeniyahh [The Effective Biological Way of Suppressing the WeedPlants under Forest Belts]. Dostizheniya nauki $i$ tekhniki APK [Achievements in Science and Technology of AIC], 2012, no. 7, pp. 37-38.

2. Zubkov A.F. Agrobiocenologicheskaya modernizatsiya zashchity rasteniy [Agrobiocenological Modernization of Plant Protection]. Saint Petersburg, VIZR Publ., 2014. 116 p.

3. Mushaeva K.B. Otsenka sovremennogo sostoyzniya agropastbishchnyh landshaftov polupustinnoy zony respubliki Kalmykiya s primeneniem GIS-tekhnologiy [Assessment of the Current State of Agropastoral Landscapes in SemiArid Areas of the Kalmykia Republic with Application of GIS-technologies]. Vestnik Volgogradskogo gosudarstvennogo universiteta. Seriya 11, Estestvennye nauki, 2015, no. 1, pp. 103-110.

4. Ivantsova E.A., Onistratenko N.V., Kholodenko A.V., Tikhonova A.A., Novochadov V.V. [Reduction of the Negative Impact on Agrocenoses by Managing Adjacent Natural and Anthropogenic Systems]. Vestnik Volgogradskogo gosudarstvennogo universiteta. Seriya 3, Ehkonomika. Ehkologiya, 2017, vol. 19 , no. 4 (41), pp. 138-146. DOI: $10.15688 /$ jvolsu3.2017.4.15.

5. Trifonova T.A., Shirkin L.A., Mishchenko N.V. Modelirovanie statsionarnykh sostoyaniy sistemy fitotsentoz-pochva (na primere 
basseyna r. Klyazma) [Simulation of Stationary States of a Phytocenosis Soil System (the Case of the Klyazma River Basin]. Pochvovedenie [Pedology], 2012, no. 8, pp. 793-801.

6. Drenovsky R.E., Grewell B.J., D’Antonio C.M., Funk J.L., James J.J., Molinari N. et al. A functional trait perspective on plant invasion. Ann. Bot., 2012, vol. 110, no. 1, pp. 141-153. DOI: 10.1093/aob/mcs 100 .

7. Ma Y., Oliveira R.S., Freitas H., Zhang C. Biochemical and molecular mechanisms of plantmicrobemetalinteractions: relevance for Phytoremediation. Front Plant Sci., 2016, no. 7. DOI: 10.3389/fpls.2016.00918

8. Helsen K., Acharya K.P., Brunet J., Cousins S.A.O., Decocq G., Hermy M., et al. Biotic and abiotic driversof intraspecific trait variation within plant populgradient. BMC Ecol., 2017, no. 17, p. 38.

9. Ivantsova E.A., Onistratenko N.V., Kholodenko A.V., Tyutyuma N.V. Ecological aspects of phytosanitary optimization of arid agrobiocenoses of the south of Russia. Bulgarian J. Agric. Sci., 2017, vol. 23 , no. 5 , pp. 834-842.

10. El-Sayed W.S., Akhkha A., El-Naggar M.Y., Elbadry M. In vitro antagonistic activity, plant growthpromoting traits and phylogenetic affiliation of rhizobacteria associated with wild plants grownin arid soil. Front. Microbiol., 2014, no. 5.

11. He M., Dijkstra F.A., Zhang K, Tan H., Yang Z., Li X. Influence of life form, taxonomy, climate, and soil properties on shoot and root concentrations of
11 elements in herbaceous plants in a temperate desert. Plant and Soil, 2016, vol. 398, no. 102, pp. 339-350.

12. Gibbons S.M., Lekberg Y., Mummey D.L., Sangwan N., Ramsey P.W, Gilbert J.A. Invasive plantsrapidly reshape soil properties in a grassland ecosystem. mSystems, 2017, vol. 2, no. 2. DOI: 10.1128/ mSystems.00178-16.

13. He M., Dijkstra F.A., Zhang K., Li X., Tan H., Gao Y. et al. Leaf nitrogen and phosphorus oftemperate desert plants in response to climate and soilnutrient availability. Scientific Reports, 2014, no. 4. DOI:https:/ /doi.org/10.1038/srep06932.

14. Ndiribe C., Pellissier L., Antonelli S., Dubuis A., Pottier J., Vittoz P. et al. Phylogenetic plant communitystructure along elevation is lineage specific. Ecol. Evol, 2013, vol. 3, no. 15, pp. 4925-4939.

15. Zefferman E., Stevens J.T., Charles G.K., Dunbar-Irwin M., Emam T., Fick S., et al. Plantcommunities in harsh sites are less invaded: a summaryof observations and proposed explanations. AoB. Plants, 2015, no. 7.

16. Kertész M., Aszalós R., Lengyel A., Ónodi G. Synergistic effects of the components of global change:Increased vegetation dynamics in open, foreststeppegrasslands driven by wildfires and year-to-year precipitationdifferences. PLoS One, 2017, vol. 12, no. 11.

17. Hudson L.N., Newbold T., Contu S., Hill S.L.L., Lysenko I., De Palma A., et al. The database ofthe PREDICTS (Projecting responses of ecologicaldiversity in changing terrestrial systems) project. Ecol. Evol., 2017, vol. 7, no. 1, pp. 145-188.

\section{Information about the Authors}

Valeriy V. Novochadov, Doctor of Sciences (Medicine), Professor, Director of the Institute of Natural Sciences, Volgograd State University, Prosp. Universitetsky, 100, 400062 Volgograd, Russian Federation, novochadov.valeriy@volsu.ru, https://orcid.org/0000-0001-6317-7418

Elena A. Ivantsova, Doctor of Sciences (Agriculture), Associate Professor, Head of Department of Ecology and Nature Management, Volgograd State University, Prosp. Universitetsky, 100, 400062 Volgograd, Russian Federation, ivantsova@volsu.ru, https://orcid.org/0000-0003-4265-9703

Pavel A. Krylov, Assistant of Department Bioengenering and Bioinformatic, Volgograd State University, Prosp. Universitetsky, 100, 400062 Volgograd, Russian Federation, p.krylov.volsu@yandex.ru, https://orcid.org/0000-0001-9587-5886

Nikolay V. Onistratenko, Candidate of Sciences (Biology), Associate Professor, Department of Ecology and Nature Management, Volgograd State University, Prosp.Universitetsky, 100, 400062 Volgograd, Russian Federation, onistratenko@volsu.ru, https://orcid.org/0000-0003-1533-1462

Anna V. Kholodenko, Candidate of Sciences(Geography),Associate Professor, Departmentof Ecology and Nature Management, Volgograd State University, Prosp.Universitetsky, 100, 400062 Volgograd, Russian Federation, kholodenko@volsu.ru, https://orcid.org/0000-0001-9053-9373

\section{Информация об авторах}

Валерий Валерьевич Новочадов, доктор медицинских наук, профессор, директор института естественных наук, Волгоградский государственный университет, просп. Университетский, 


\section{ЭколОГИя}

100, 400062 г. Волгоград, Российская Федерация, novochadov.valeriy@volsu.ru, https://orcid.org/00000001-6317-7418

Елена Анатольевна Иванцова, доктор сельскохозяйственных наук, доцент, заведующая кафедрой экологии и природопользования, Волгоградский государственный университет, просп. Университетский, 100, 400062 г. Волгоград, Российская Федерация, ivantsova@volsu.ru, https://orcid.org/ 0000-0003-4265-9703

Павел Андреевич Крылов, ассистент кафедры биоинженерии и биоинформатики, Волгоградский государственный университет, просп. Университетский, 100, 400062 г. Волгоград, Российская Федерация, p.krylov.volsu@yandex.ru, https://orcid.org/0000-0001-9587-5886

Николай Владимирович Онистратенко, кандидат биологических наук, доцент кафедры экологии и природопользования, Волгоградский государственный университет просп. Университетский, 100, 400062 г. Волгоград, Российская Федерация, onistratenko@volsu.ru, https://orcid.org/0000-0003-1533-1462

Анна Викторовна Холоденко, кандидат географических наук, доцент кафедры экологии и природопользования, Волгоградский государственный университет, просп. Университетский, 100, 400062 г. Волгоград, Российская Федерация, kholodenko@volsu.ru, https://orcid.org/0000-00019053-9373 